\title{
Whole genome SNP typing to investigate methicillin-resistant Staphylococcus aureus carriage in a health-care provider as the source of multiple surgical site infections
}

Chandler C. Roe ${ }^{1 *}$, Kimberly S. Horn² ${ }^{2}$ Elizabeth M. Driebe ${ }^{1}$, Jolene Bowers ${ }^{1}$, Joel A. Terriquez ${ }^{2}$, Paul Keim ${ }^{1}$ and David M. Engelthaler ${ }^{1}$

\begin{abstract}
Background: Prevention of nosocomial transmission of infections is a central responsibility in the healthcare environment, and accurate identification of transmission events presents the first challenge. Phylogenetic analysis based on whole genome sequencing provides a high-resolution approach for accurately relating isolates to one another, allowing precise identification or exclusion of transmission events and sources for nearly all cases. We sequenced 24 methicillin-resistant Staphylococcus aureus (MRSA) genomes to retrospectively investigate a suspected point source of three surgical site infections (SSIS) that occurred over a one-year period. The source of transmission was believed to be a surgical team member colonized with MRSA, involved in all surgeries preceding the SSI cases, who was subsequently decolonized. Genetic relatedness among isolates was determined using whole genome single nucleotide polymorphism (SNP) data.

Results: Whole genome SNP typing (WGST) revealed 283 informative SNPs between the surgical team member's isolate and the closest SSI isolate. The second isolate was 286 and the third was thousands of SNPs different, indicating the nasal carriage strain from the surgical team member was not the source of the SSIs. Given the mutation rates estimated for S. aureus, none of the SSI isolates share a common ancestor within the past 16 years, further discounting any common point source for these infections. The decolonization procedures and resources spent on the point source infection control could have been prevented if WGST was performed at the time of the suspected transmission, instead of retrospectively.

Conclusions: Whole genome sequence analysis is an ideal method to exclude isolates involved in transmission events and nosocomial outbreaks, and coupling this method with epidemiological data can determine if a transmission event occurred. These methods promise to direct infection control resources more appropriately.
\end{abstract}

Keywords: Nasal carriage, Surgical site infections, MRSA, Transmission, Whole genome sequencing

\footnotetext{
* Correspondence: croe@tgen.org

${ }^{1}$ Pathogen Genomics Division, Translational Genomics Research Institute,

3051 W. Shamrell Blvd., Suite 106, Flagstaff, AZ 86001, USA

Full list of author information is available at the end of the article
}

\section{Biomed Central}

(c) The Author(s). 2016 Open Access This article is distributed under the terms of the Creative Commons Attribution 4.0 International License (http://creativecommons.org/licenses/by/4.0/), which permits unrestricted use, distribution, and reproduction in any medium, provided you give appropriate credit to the original author(s) and the source, provide a link to the Creative Commons license, and indicate if changes were made. The Creative Commons Public Domain Dedication waiver (http://creativecommons.org/publicdomain/zero/1.0/) applies to the data made available in this article, unless otherwise stated. 


\section{Background}

Surgical site infections (SSIs) account for $31 \%$ of all healthcare-associated infections in the United States [1]. A critical risk factor for the development of a SSI is the severity of wound contamination during surgery $[2,3]$. As one of the most predominant organisms colonizing the skin, Staphylococcus aureus is a common causative agent of SSI [4], and methicillin-resistant S. aureus (MRSA) accounts for $15 \%$ of reported SSIs [5]. The most significantly associated independent circumstance for the development of a $S$. aureus SSI is nasal carriage by the patient [3]. Studies that examined perioperative decolonization of patients using intranasal mupirocin showed a significant decrease in the risk of developing a SSI [6-8]. The risk of a $S$. aureus SSI associated with $S$. aureus nasal carriage or colonization of surgical team members is unknown.

The implementation of whole genome sequencing (WGS) in the clinical setting to closely analyze isolates has allowed for precise identification and characterization of putative transmission events among patients. WGS also allows for high resolution analysis of source tracing in hospitals which can have the potential to impact hospitalbased outbreak investigations and infection prevention practices [9-12]. To our knowledge, however, no study has investigated MRSA carriage among surgical staff members as a source of MRSA transmission to surgical patients using WGST.

In this study, a hospital infection control team identified a cluster of MRSA SSIs from a single surgical team. Antibiotic susceptibility profiles suggested that the cases were related. The surgical team in question was screened for nasal carriage by the infection control team and one member tested positive for MRSA by PCR, as well as by culture. The surgical team member was decolonized per hospital protocol, and the MRSA decolonization was documented as successful, based on further nasal screening. In this study, we retrospectively examine the MRSA strain from the colonized surgical team member along with patient and control strains to determine whether it was the source of the cluster of SSIs using whole genome single nucleotide polymorphism (SNP) typing (WGST) [13-15]. These results demonstrate the utility of WGST for hospital molecular epidemiology and provide confirmation that the source of infection for three patients was not related to the surgical team member isolate.

\section{Methods}

\section{Surveillance}

From February 2010 to August 2011, 24 MRSA isolates were obtained from 18 patients and one surgical team member in a rural 280-bed hospital (Table 1). Isolates were obtained from remaining samples previously collected for in-house testing as approved by the Institutional
Table 1 Clinical histories of patients with MRSA infections, including suspected index case

\begin{tabular}{|c|c|c|c|}
\hline Patient & Isolates & Source & Year Collected \\
\hline $\begin{array}{l}\text { Surgical Team } \\
\text { Member }\end{array}$ & 1 & Nasal & February 2011 \\
\hline Case 2 & 1 & Blood & February 2011 \\
\hline Case 3a & 3 & Abdominal fluid & September 2010 \\
\hline Case $3 b$ & - & Anal fistula & August 2011 \\
\hline Case 3c & - & Sputum & August 2011 \\
\hline Case 4 & 1 & Deep wound & July 2010 \\
\hline Hospital Control 1 & 1 & Tissue & March 2010 \\
\hline Hospital Control 2 & 1 & Incision & December 2010 \\
\hline Hospital Control 3 & 1 & Joint fluid & September 2010 \\
\hline Hospital Control 4a & 2 & Tissue & March 2010 \\
\hline Hospital Control 4b & - & Deep wound & March 2010 \\
\hline Hospital Control 5 & 1 & Tissue & November 2010 \\
\hline Hospital Control 6 & 1 & Tissue & October 2010 \\
\hline Hospital Control 7 & 1 & Deep wound & December 2010 \\
\hline Hospital Control 8a & 2 & Abdominal fluid & February 2011 \\
\hline Hospital Control 8b & - & Abdominal fluid & February 2011 \\
\hline Healthcare Control 9a & 2 & Head & February 2011 \\
\hline Healthcare Control 9b & - & Head & February 2011 \\
\hline Healthcare Control 10 & 1 & Right stump & March 2011 \\
\hline Healthcare Control 11 & 1 & Urine & February 2011 \\
\hline Community Control 12 & 1 & Blood & March 2011 \\
\hline Community Control 13 & 1 & Boil & October 2010 \\
\hline Community Control 14 & 1 & Abscess groin & February 2011 \\
\hline Community Control 15 & 1 & $\begin{array}{l}\text { Excision site } \\
\text { abdominal }\end{array}$ & March 2011 \\
\hline
\end{tabular}

Multiple samples taken from individuals are labeled as "a", "b", and "c"

Review Board of the participating institution. No patient consent was needed as samples obtained were isolates only. The isolates fell into three groups; the first group comprised the surgical team member's isolate (suspected point source) and three patients' SSI isolates. The three isolates were from patients who developed MRSA surgical site infections following surgical procedures by the same medical team. The surgical team in question was screened for nasal carriage and one member tested positive for MRSA by the GeneXpert Infinity MRSA PCR (Cepheid), and subsequently MRSA was cultured from the original swab providing the surgical team member isolate. The surgical team member's isolate was tested and confirmed positive for mecA, an assay included in the GeneXpert PCR assay.

The second group consisted of 10 background isolates considered to have no association with the first group of samples but were also from SSIs, collected randomly from the regular sample flow at the hospital. The third 
group comprised 10 background samples, also randomly collected, from outpatients and patients admitted to the hospital with MRSA infections. These isolates were sourced from blood, sputum, wound and urine specimens. In all three groups of isolates, multiple samples from individual patients, labeled as "a" and " $\mathrm{b}$ ", were taken over time to serve as a control threshold for genetic similarity and relatedness.

\section{DNA sequencing}

Isolates were grown on trypticase soy agar media and DNA was prepared using DNeasy Blood \& Tissue Kit as described by the manufacturer (Qiagen, Valencia, CA) with the addition of lysostaphin to the grampositive extraction protocol from Qiagen. The DNA samples were prepared for multiplexed, paired-end sequencing with a 500 base pair insert using Library Preparation Kit with Standard PCR Library Amplification (KAPA Biosystems, Woburn, MA). A 100 bp read paired-end run was used for all twenty-four isolates on the GAIIx sequencing platform (Illumina, Inc. San Diego, CA).

\section{SNP phylogenetic analysis}

A phylogeny of all the MRSA isolates was constructed based on a matrix that tabulates all SNPs among the genomes of the isolates by their locus within a reference genome. The matrix was generated using the Northern Arizona SNP Pipeline (NASP) [16]. NASP aligns DNA sequencing reads to a reference, identifies SNPs and filters SNP loci based on user-defined parameters as previously described $[14,15,17-19]$. NASP generated a matrix for this study by aligning sequence reads from the 24 isolates to the reference genome, FPR3757 (NCBI accession number: NC_007793), using Novoalign (Novocraft.com). Reads that mapped to multiple locations within the reference genome were excluded from the alignments as were reads containing insertions or deletions. SNPs were identified in the alignments using the Genome Analysis Toolkit (GATK) [20]. Only SNP loci found throughout all samples were used for the phylogenetic analysis. Additionally, SNPs had to be in $>90 \%$ of the reads and have minimum $10 \times$ coverage to be included in a final matrix. MUMmer version 3.22 [21] was used to identify duplicated regions within FPR3757 and SNP loci within these regions were removed from the final analysis. The phylogenetic analysis of the high-quality core genome SNP matrix was performed with $M E G A$ version 5.05 [22] using the maximum parsimony algorithm and bootstrap analysis with 1,000 replicates. Read depth statistics and reference coverage were determined from NASP. The whole genome sequence read files were deposited in the NCBI Sequence Read Archive under BioProject ID PRJNA255788. Read data were also used to identify the multi-locus sequence type (MLST) as well as antibiotic resistant gene profiles for each sample using SRST2 [23].

\section{Results}

\section{Genomic investigation}

The sequence analysis provided appropriate depth and breadth of sequence coverage across all isolates to conduct robust WGST analysis. Mean quality breadth of the reference genome FPR3757 for all samples was $\geq 91.36 \%$ with a mean read-depth of 103X (Additional file 1: Table $\mathrm{S} 1$ ). The phylogeny constructed was based on 18,520 parsimony informative SNPs and revealed two distinct clades (Fig. 1). MLST analysis using WGS data identified these clades as two distinct clonal complexes: CC5, which is known to include a major clone historically associated with healthcare-associated infections; and CC8, a major clonal group of largely community-acquired strains. CC5 and CC8 represent two distantly related lineages of $S$. aureus that are common in hospitals across the country [24, 25].

WGST analysis demonstrated that no obvious transmission event occurred between the colonized surgical team member and patients. First, the two distinct clades in the phylogenetic tree, CC5 and CC8, are separated by 17,042 SNPs. The surgical team member isolate and one of the MRSA SSI cluster isolates, Case 3, are located in CC5 and CC8 respectively. Second, the surgical team member isolate is 283 SNPs different from the closest case isolate, Case 2, and even more distant from the third, Case 4. Estimates of the mutation rate for $S$. aureus have been calculated repeatedly at a rate of approximately $3.3 \times 10^{-6}$ mutations per site per year, or one core genome SNP every 6 to 7 weeks [26-28]. Using this estimate, there should be approximately 7 to 8 SNPs per year after strains diverge from a common ancestor due to baseline mutation alone. Given their 283 SNP separation, the isolates from the surgical team member and Case 2 had a common ancestor more than 16 years prior to the surgery. Case 4, the other suspected related isolate, was as distant from the surgical team member isolate as Case 2, with a 285 SNP differentiation.

Additionally, in order to determine epidemiologically related and unrelated isolates using WGST, a threshold was established from a set of related isolates for our study, using multiple samples taken from individual patients over time (Healthcare Control 9a and 9b, Case 3, $3 \mathrm{a}$ and $3 \mathrm{~b}$, Hospital Control $8 \mathrm{a}$ and $8 \mathrm{~b}$ and Hospital Control $4 \mathrm{a}$ and $4 \mathrm{~b}$ ). The average pairwise distance between each set of related isolates was 2.3 SNPs with the exception of Case 3. Case 3, 3a and $3 b$ were from the same patient over the span of one year and taken from multiple body sites. These three isolates contained 21 


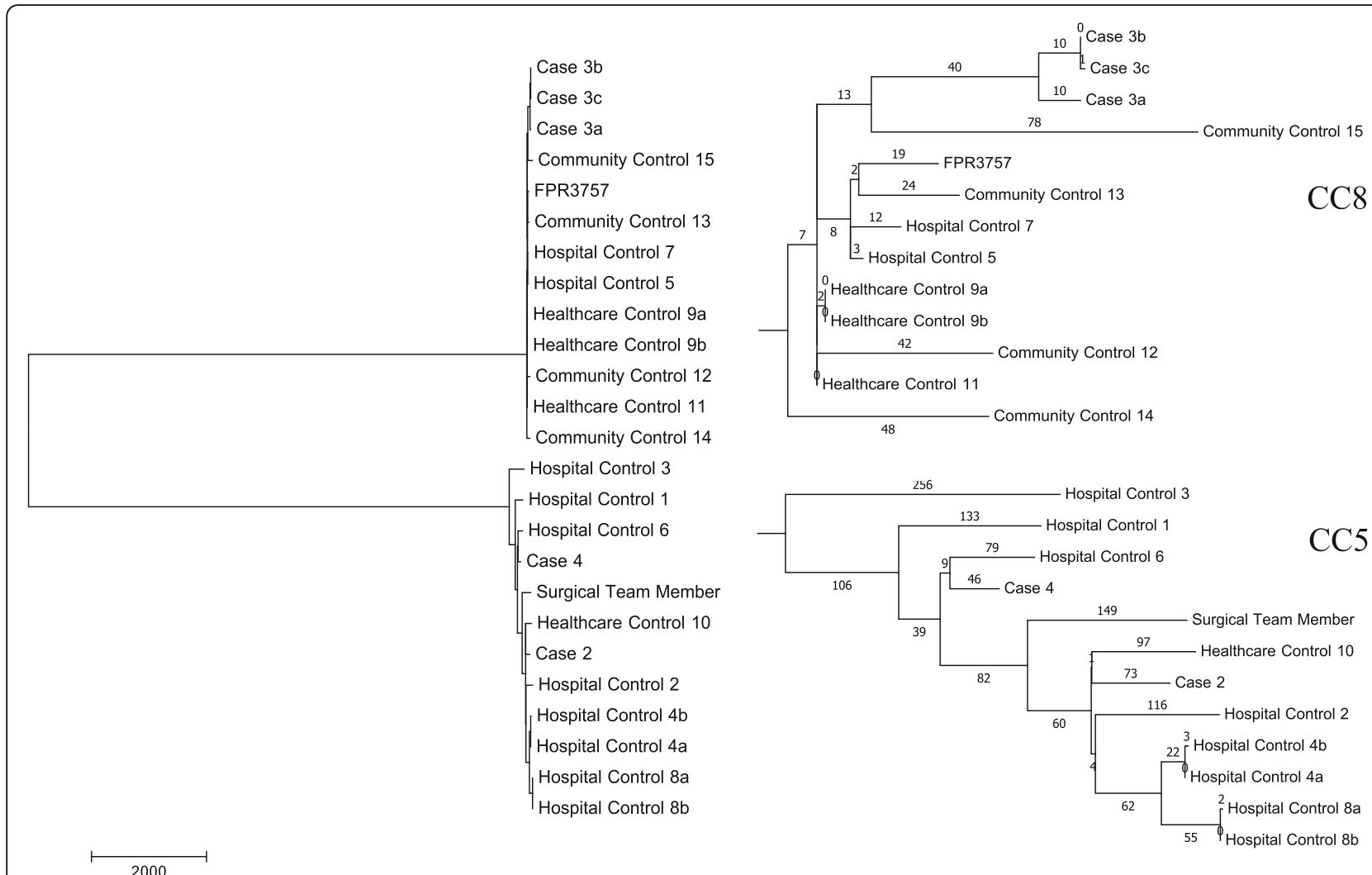

Fig. 1 Phylogenetic SNP analysis. Unrooted phylogenetic SNP analysis based on whole genome sequence data of 24 MRSA isolates using the maximum parsimony algorithm

SNPs among them, with no more than 10 SNPs between any two isolates; however, this number is still within the predicted baseline mutation rate of $S$. aureus. Healthcare control samples 9a, 9b and 11, collected from two different patients, had two SNP differences separating them, indicating a likely recent transmission event, probably within the long-term care facility where both patients resided.

\section{Discussion}

Our investigation indicates that the surgical team member isolate was not the source of a transmission event and that no evidence of transmission occurred among the suspect cases. It is well established that humans are commonly colonized with $S$. aureus, with a fraction of the population being carriers of MRSA; a recent review, published in 2014, investigating MRSA carriage among healthcare workers in non-outbreak settings in Europe and the United States estimated between under $1 \%$ and $15 \%$ of hospital staff are MRSA carriers [29]. A recent study from the Netherlands, published in 2015, estimates $S$. aureus carriage among surgeons as high as $45.4 \%$ [30]. A high incidence of both methicillin-susceptible
S. aureus (MSSA) and MRSA nasal carriage are exacerbating the increasing number of healthcare-associated $S$. aureus infections in patient care facilities [31]. Reducing patient colonization has been hypothesized to help in the prevention of MRSA transmission and infection [32, 33]. However, the impact of MRSA carriage by medical providers and hospital ancillary staff when compared to the MRSA nasal carriage rate of patients, in association with the incidence of MRSA nosocomial infections, is still not well understood but has been speculated as a source of patient infection $[30,34,35]$. Such provider to patient transmission would have significant liability, reimbursement and risk management implications for both providers and healthcare facilities. In this study, we used high-resolution techniques to compare a MRSA isolate carried by a surgical team member to the MRSA isolates of that surgical team member's patients who had postoperative SSIs. WGST confirmed that transmission events did not occur between a healthcare provider and the surgical patients examined. In order to determine accurate epidemiological association, background control isolates from the hospital and community were compared to the suspected cluster isolates. By including these background 
isolates, if a transmission event had occurred, we would have observed a clear phylogenetic distinction between the background isolates and the isolates involved in the transmission event. However, we identified more than 17,000 parsimony informative SNPs among the 24 isolates and we did not observe a distinct grouping of the isolates that were originally thought to be surgery-associated transmission events. Additionally, an WGS-MLST analysis confirmed that the surgeon's isolate was in fact a single locus variant (ST225) of ST5 and a distinct lineage from the other isolates (Additional file 2: Table S2). Furthermore, a review of the presence/absence of critical antibiotic resistance genes did not reveal any patterns of interest among the isolates (Additional file 3: Table S3).

WGST has been successfully used as a molecular epidemiology tool for numerous outbreak investigations [13-15, 17-19, 36], replacing older standards such as PFGE due to increased sensitivity and specificity [37]. Our study further establishes the effectiveness of WGST for epidemiological investigations within a hospital setting, which is especially critical for rapid analysis during an ongoing outbreak. Interestingly, we identified a previously unrecognized transmission event outside the hospital that likely would not have been discovered without WGST. Furthermore, this study highlights the need for additional investigation to identify the source of hospital-acquired MRSA infections, including but not limited to medical providers, hospital staff members and the patient's own nasal colonization, as well as the importance of source tracing to correctly identify an outbreak.

Implementing the reported mutation rate within our data further weakens our hypothesis of a healthcare provider-related transmission, with at least 16 years of evolutionary time between the isolates from the surgical team member and the respective patients. Furthermore, the high resolution of WGST provides a genetic threshold to gauge relatedness between isolates collected from a single patient from multiple body sites and over time in comparison to isolates from unrelated patients. This genetic relatedness framework also allowed for the detection of a previously unrecognized MRSA transmission event. These data also suggest importation of strains circulating in other care facilities is a potential source for hospital-acquired infections.

A limitation of this study is the sequencing of a single colony from the suspected source. Recent research shows the bacterial diversity within a host can impede accurate depiction of transmission events [38]. Pathogen genetic diversity within a host can be widespread and may be due to numerous transmissions from multiple sources [38]. Furthermore, S. aureus studies reveal carriage of numerous sequence types within a single host likely due to multiple independent transmissions [39, 40]. In order to account for within-host diversity and reduce the risk of falsely interpreting results, it will be important to increase the sampling of isolates from the suspected source in future investigations. However, the fact that none of the three SSI isolates were related to one another provides evidence against a point source regardless of the single isolate sampling from the surgical team member.

\section{Conclusions}

The lack of a MRSA transmission event between the colonized surgical team member and the surgical patients shown here has implications in the healthcare field, from infection prevention to hospital epidemiology and healthcare reimbursement. These findings were only apparent through the use of WGST. Low resolution strain typing methods like antibiogram profiles may lead to erroneous conclusions, and may instigate inappropriate, costly, and ineffective infection control measures as was the case here, as well as limit reimbursement for inpatient services from third-party payers (e.g., CMS) [41]. The accurate determination or repudiation of a healthcare-associated outbreak or cluster will prevent unnecessary, disruptive and costly infection prevention procedures and allow the implementation of these control measures when they are appropriate. With the increasing reality of clinical laboratory bacterial sequencing and accessible analysis tools, healthcare and public health systems would do well to maintain isolate and/or sequence repositories of local critical nosocomial pathogens to quickly detect and analyze possible hospital associated infection (HAI) outbreaks.

\section{Additional files}

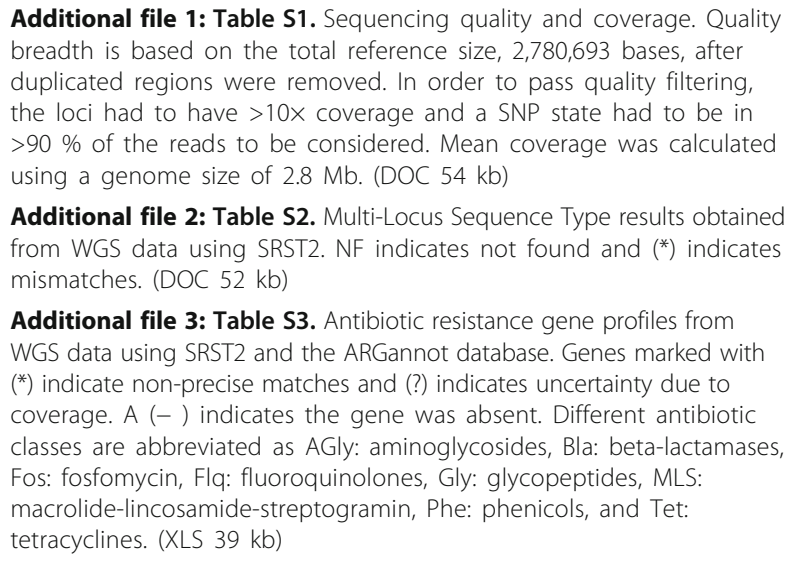

Additional file 2: Table S2. Multi-Locus Sequence Type results obtained from WGS data using SRST2. NF indicates not found and $\left(^{*}\right)$ indicates mismatches. (DOC $52 \mathrm{~kb}$ )

Additional file 3: Table S3. Antibiotic resistance gene profiles from WGS data using SRST2 and the ARGannot database. Genes marked with $\left(^{*}\right)$ indicate non-precise matches and (?) indicates uncertainty due to coverage. A (-) indicates the gene was absent. Different antibiotic classes are abbreviated as AGly: aminoglycosides, Bla: beta-lactamases, Fos: fosfomycin, Flq: fluoroquinolones, Gly: glycopeptides, MLS: macrolide-lincosamide-streptogramin, Phe: phenicols, and Tet: tetracyclines. (XLS $39 \mathrm{~kb}$ )

\section{Abbreviations}

GATK: Genome analysis toolkit; HAl: Hospital associated infection; MLST: Multi-locus sequence type; MRSA: Methicillin resistant Staphylococcus aureus; MSSA: Methicillin resistant Staphylococcus aureus; NASP: Northern Arizona SNP pipeline; PCR: Polymerase chain reaction; PFGE: Pulse-field gel electrophoresis; SNP: Single nucleotide polymorphism; SSI: Surgical site infection; ST: sequence type; WGS: Whole genome sequencing; WGST: Whole genome SNP typing 


\section{Acknowledgements}

Not applicable.

\section{Funding}

This work was supported by the National Institute of Health

[grant U01Al066581] and The Flinn Foundation.

\section{Availability of data and materials}

The whole genome sequence read files were deposited in the NCBI Sequence Read Archive under BioProject ID PRJNA255788.

\section{Authors' contributions}

CR analyzed the data and contributed to writing and revising the manuscript. KH contributed to the design of the study and sample collection. ED contribute to the design of the study, the analysis and writing and revising the manuscript. JB contributed to study design, processing samples and writing and revising the manuscript. JT contributed to writing the manuscript and the interpretation of the data. PK contributed to the study design, writing and revising the manuscript. DE contributed to the study design, writing and revising the manuscript. All authors read and approved the manuscript.

\section{Competing interest}

The authors declare that they have no competing interests.

\section{Consent for publication}

Not applicable.

\section{Ethics approval and consent to participate}

Isolates were obtained from remaining samples previously collected for in-house testing as approved by the Institutional Review Board of the participating institution. No patient consent was needed as samples obtained were isolates only. This study only utilized isolates and therefore did not need ethics approval.

\section{Author details}

'Pathogen Genomics Division, Translational Genomics Research Institute, 3051 W. Shamrell Blvd., Suite 106, Flagstaff, AZ 86001, USA. ${ }^{2}$ Flagstaff Medical Center, Flagstaff, AZ, USA.

\section{Received: 27 April 2016 Accepted: 26 October 2016}

\section{Published online: 14 November 2016}

\section{References}

1. Magill SS, Hellinger W, Cohen J, Kay R, Bailey C, Boland B, Carey D, de Guzman J, Dominguez K, Edwards J, Goraczewski L, Horan T, Miller M, Phelps M, Saltford R, Seibert J, Smith B, Starling P. Viergutz B, Walsh K, Rathore M, Guzman N, Fridkin S. Prevalence of Healthcare-Associated Infections in Acute Care Hospitals in Jacksonville, Florida. 2012.

2. Weigelt JA. Risk of wound infections in trauma patients. Am J Surg. 1985;150:782-4.

3. Kalmeijer MD, Bollen EVN, Bogaers D, De Baere GAJ, Kluytmans JAJW. Nasal carriage of staphylococcus aureus is a major risk factor for surgical site infections in orthopedic surgery. Infect Control Hosp Epidemiol. 2000;21:319-23.

4. Chen AF, Wessel CB, Rao N. Staphylococcus aureus screening and decolonization in orthopaedic surgery and reduction of surgical site infections. Clin Orthop Relat Res. 2013:471:2383-99.

5. Anderson DJ, Kaye KS, Chen LF, Schmader KE, Choi Y, Sloane R, Sexton DJ. Clinical and financial outcomes due to methicillin resistant Staphylococcus aureus surgical site infection: a multi-center matched outcomes study. PLoS One. 2009:4:e8305.

6. Wilcox M, Hall J, Pike H, Templeton P, Fawley W, Parnell P, Verity P. Use of perioperative mupirocin to prevent methicillin-resistant Staphylococcus aureus (MRSA) orthopaedic surgical site infections. J Hosp Infect. 2003; 54:196-201

7. Gernaat-van der Sluis AJ, Hoogenboom-Verdegaal AM, Edixhoven PJ, Spies-van Rooijen NH. Prophylactic mupirocin could reduce orthopedic wound infections. 1,044 patients treated with mupirocin compared with 1,260 historical controls. Acta Orthop Scand. 1998;69:412-4.
8. Cimochowski GE, Harostock MD, Brown R, Bernardi M, Alonzo N, Coyle K. Intranasal mupirocin reduces sternal wound infection after open heart surgery in diabetics and nondiabetics. Ann Thorac Surg. 2001;71:1572-8. discussion 1578-9.

9. Harris SR, Cartwright EJP, Török ME, Holden MTG, Brown NM, Ogilvy-Stuart AL, Ellington MJ, Quail MA, Bentley SD, Parkhill J, Peacock SJ. Whole-genome sequencing for analysis of an outbreak of meticillin-resistant Staphylococcus aureus: a descriptive study. Lancet Infect Dis. 2013;13:130-6.

10. Köser CU, Holden MTG, Ellington MJ, Cartwright EJP, Brown NM, OgilvyStuart AL, Hsu LY, Chewapreecha C, Croucher NJ, Harris SR, Sanders M, Enright MC, Dougan G, Bentley SD, Parkhill J, Fraser LJ, Betley JR, Schulz-Trieglaff OB, Smith GP, Peacock SJ. Rapid whole-genome sequencing for investigation of a neonatal MRSA outbreak. N Engl J Med. 2012;366:2267-75.

11. Snitkin ES, Zelazny AM, Thomas PJ, Stock F, Henderson DK, Palmore TN, Segre JA. Tracking a hospital outbreak of carbapenem-resistant Klebsiella pneumoniae with whole-genome sequencing. Sci Transl Med. 2012;4:148ra116.

12. Halachev MR, Chan J, Constantinidou Cl, Cumley N, Bradley C, Smith-Banks M, Oppenheim B, Pallen MJ. Genomic epidemiology of a protracted hospital outbreak caused by multidrug-resistant Acinetobacter baumannii in Birmingham, England. Genome Med. 2014;6:70.

13. Wendt JM, Kaul D, Limbago BM, Ramesh M, Cohle S, Denison AM, Driebe EM, Rasheed JK, Zaki SR, Blau DM, Paddock CD, McDougal LK, Engelthaler DM, Keim PS, Roe CC, Akselrod H, Kuehnert MJ, Basavaraju SV. Transmission of methicillin-resistant Staphylococcus aureus infection through solid organ transplantation: confirmation via whole genome sequencing. Am J Transplant. 2014;14:2633-9.

14. Litvintseva AP, Hurst S, Gade L, Frace MA, Hilsabeck R, Schupp JM, Gillece JD, Roe C, Smith D, Keim P, Lockhart SR, Changayil S, Weil MR, MacCannell $D R$, Brandt ME, Engelthaler DM. Whole-genome analysis of Exserohilum rostratum from an outbreak of fungal meningitis and other infections. J Clin Microbiol. 2014;52:3216-22.

15. Engelthaler DM, Hicks ND, Gillece JD, Roe CC, Schupp JM, Driebe EM, Gilgado F, Carriconde F, Trilles L, Firacative C, Ngamskulrungroj P, Castañeda E, dos Santos Lazera M, Melhem MSC, Pérez-Bercoff A, Huttley G, Sorrell TC, Voelz K, May RC, Fisher MC, Thompson GR, Lockhart SR, Keim P, Meyer W. Cryptococcus gattii in North American Pacific Northwest: whole-population genome analysis provides insights into species evolution and dispersal. MBio. 2014:5:e01464-14.

16. Sahl JW, Lemmer D, Travis J, Schupp J, Gillece J, Aziz M, Driebe E, Drees K, Hicks N, Williamson C, Hepp C, Smith D, Roe C, Engelthaler D, Wagner D, Keim P. The Northern Arizona SNP Pipeline (NASP): Accurate, Flexible, and Rapid Identification of SNPs in WGS Datasets. Microbial Genomics. 2016;2.

17. Litvintseva AP, Marsden-Haug N, Hurst S, Hill H, Gade L, Driebe EM, Ralston C, Roe C, Barker BM, Goldoft M, Keim P, Wohrle R, Thompson GR, Engelthaler DM, Brandt ME, Chiller T. Valley fever: finding new places for an old disease: coccidioides immitis found in Washington state soil associated with recent human infection. Clin Infect Dis. 2015;60:e1-3.

18. Engelthaler DM, Chiller T, Schupp JA, Colvin J, Beckstrom-Sternberg SM, Driebe EM, Moses T, Tembe W, Sinari S, Beckstrom-Sternberg JS, Christoforides A, Pearson JV, Carpten J, Keim P, Peterson A, Terashita D, Balajee SA. Next-generation sequencing of Coccidioides immitis isolated during cluster investigation. Emerg Infect Dis. 2011;17:227-32.

19. Etienne KA, Gillece J, Hilsabeck R, Schupp JM, Colman R, Lockhart SR, Gade L, Thompson EH, Sutton DA, Neblett-Fanfair R, Park BJ, Turabelidze G, Keim $P$, Brandt ME, Deak E, Engelthaler DM. Whole genome sequence typing to investigate the Apophysomyces outbreak following a tornado in Joplin, Missouri, 2011. PLoS One. 2012;7:e49989.

20. DePristo MA, Banks E, Poplin R, Garimella KV, Maguire JR, Hartl C, Philippakis AA, del Angel G, Rivas MA, Hanna M, McKenna A, Fennell TJ, Kernytsky AM, Sivachenko AY, Cibulskis K, Gabriel SB, Altshuler D, Daly MJ. A framework for variation discovery and genotyping using next-generation DNA sequencing data. Nat Genet. 2011;43:491-8.

21. Kurtz S, Phillippy A, Delcher AL, Smoot M, Shumway M, Antonescu C, Salzberg SL. Versatile and open software for comparing large genomes. Genome Biol. 2004;5:R12.

22. Tamura K, Peterson D, Peterson N, Stecher G, Nei M, Kumar S. MEGA5 molecular evolutionary genetics analysis using maximum likelihood, evolutionary distance, and maximum parsimony methods. Mol Biol Evol. 2011;28:2731-9. 
23. Inouye M, Dashnow H, Raven L-A, Schultz MB, Pope BJ, Tomita T, Zobel J, Holt KE. SRST2: Rapid genomic surveillance for public health and hospital microbiology labs. Genome Med. 2014;6:90.

24. Monecke S, Coombs G, Shore AC, Coleman DC, Akpaka P, Borg M, Chow H, Ip $M$, Jatzwauk $L$, Jonas $D$, Kadlec $K$, Kearns A, Laurent F, O'Brien FG, Pearson J, Ruppelt A, Schwarz S, Scicluna E, Slickers P, Tan H-L, Weber S, Ehricht R. A field guide to pandemic, epidemic and sporadic clones of methicillin-resistant Staphylococcus aureus. PLoS One. 2011;6:e17936.

25. Uhlemann A-C, Otto M, Lowy FD, DeLeo FR. Evolution of community- and healthcare-associated methicillin-resistant Staphylococcus aureus. Infect Genet Evol. 2014;21:563-74

26. Harris SR, Feil EJ, Holden MTG, Quail MA, Nickerson EK, Chantratita N, Gardete S, Tavares A, Day N, Lindsay JA, Edgeworth JD, de Lencastre H, Parkhill J, Peacock SJ, Bentley SD. Evolution of MRSA during hospital transmission and intercontinental spread. Science. 2010:327:469-74.

27. Nübel U, Dordel J, Kurt K, Strommenger B, Westh H, Shukla SK, Zemlicková $H$, Leblois $R$, Wirth $T$, Jombart $T$, Balloux $F$, Witte W. A timescale for evolution, population expansion, and spatial spread of an emerging clone of methicillin-resistant Staphylococcus aureus. PLoS Pathog. 2010;6:e1000855.

28. Young BC, Golubchik T, Batty EM, Fung R, Larner-Svensson $H_{\text {, }}$ Votintseva AA, Miller RR, Godwin H, Knox K, Everitt RG, lqbal Z, Rimmer AJ, Cule M, Ip CLC, Didelot X, Harding RM, Donnelly P, Peto TE, Crook DW, Bowden R, Wilson DJ. Evolutionary dynamics of Staphylococcus aureus during progression from carriage to disease. Proc Natl Acad Sci U S A. 2012;109:4550-5.

29. Dulon M, Peters C, Schablon A, Nienhaus A, Gagliotti C, Balode A, Baquero F, Degener J, Grundmann H, Gur D, Jarlier V, Kahlmeter G, Monen J, Monnet D, Rossolini G, Suetens C, Weist K, Heuer O, Dulon M, Haamann F, Peters C, Schablon A, Nienhaus A, Acton D, Plat-Sinnige M, van Wamel W, de Groot $\mathrm{N}$, van Belkum A, Albrich W, Harbarth S, et al. MRSA carriage among healthcare workers in non-outbreak settings in Europe and the United States: a systematic review. BMC Infect Dis. 2014;14:363.

30. van Vugt JLA, Coelen RJS, van Dam DW, Winkens B, Derikx JPM, Heddema ER, Stoot JHMB. Nasal carriage of staphylococcus aureus among surgeons and surgical residents: a nationwide prevalence study. Surg Infect (Larchmt). 2015;16:178-82.

31. del Rio A, Cervera C, Moreno A, Moreillon P, Miró JM. Patients at risk of complications of Staphylococcus aureus bloodstream infection. Clin Infect Dis. 2009;48 Suppl 4:S246-53.

32. Huh HJ, Kim ES, Chae SL. Methicillin-resistant Staphylococcus aureus in nasal surveillance swabs at an intensive care unit: an evaluation of the LightCycler MRSA advanced test. Ann Lab Med. 2012;32:407-12.

33. Davis KA, Stewart JJ, Crouch HK, Florez CE, Hospenthal DR. Methicillinresistant Staphylococcus aureus (MRSA) nares colonization at hospital admission and its effect on subsequent MRSA infection. Clin Infect Dis. 2004;39:776-82

34. Rongpharpi SR, Hazarika NK, Kalita H. The prevalence of nasal carriage of Staphylococcus aureus among healthcare workers at a tertiary care hospital in assam with special reference to MRSA. J Clin Diagn Res. 2013;7:257-60.

35. Shibabaw A, Abebe T, Mihret A. Nasal carriage rate of methicillin resistant staphylococcus aureus among dessie referral hospital health care workers; dessie, Northeast Ethiopia. Antimicrob Resist Infect Control. 2013;2:25.

36. Hendriksen RS, Price LB, Schupp JM, Gillece JD, Kaas RS, Engelthaler DM, Bortolaia V, Pearson T, Waters AE, Upadhyay BP, Shrestha SD, Adhikari S, Shakya G, Keim PS, Aarestrup FM. Population genetics of Vibrio cholerae from Nepal in 2010: evidence on the origin of the Haitian outbreak. MBio. 2011;2:e00157-11.

37. Deng X, Shariat N, Driebe EM, Roe CC, Tolar B, Trees E, Keim P, Zhang W, Dudley EG, Fields PI, Engelthaler DM. Comparative analysis of subtyping methods against a whole-genome-sequencing standard for Salmonella enterica serotype Enteritidis. J Clin Microbiol. 2015;53:212-8.

38. Worby CJ, Lipsitch M, Hanage WP. Within-host bacterial diversity hinders accurate reconstruction of transmission networks from genomic distance data. PLoS Comput Biol. 2014;10:e1003549.

39. Mongkolrattanothai $K$, Gray BM, Mankin P, Stanfill AB, Pearl RH, Wallace LJ, Vegunta RK. Simultaneous carriage of multiple genotypes of Staphylococcus aureus in children. J Med Microbiol. 2011;60(Pt 3):317-22.
40. Cespedes C, Said-Salim B, Miller M, Lo S-H, Kreiswirth BN, Gordon RJ, Vavagiakis P, Klein RS, Lowy FD. The clonality of Staphylococcus aureus nasal carriage. J Infect Dis. 2005;191:444-52.

41. Stone PW, Pogorzelska M, Graham D, Jia H, Uchida M, Larson EL. California hospitals response to state and federal policies related to health care-associated infections. Policy Polit Nurs Pract. 2011;12:73-81.

\section{Submit your next manuscript to BioMed Central and we will help you at every step:}

- We accept pre-submission inquiries

- Our selector tool helps you to find the most relevant journal

- We provide round the clock customer support

- Convenient online submission

- Thorough peer review

- Inclusion in PubMed and all major indexing services

- Maximum visibility for your research

Submit your manuscript at www.biomedcentral.com/submit 